\title{
Testosterone Levels in Dominant Sociable Males Are Lower than in Solitary Roamers: Physiological Differences between Three Male Reproductive Tactics in a Sociably Flexible Mammal
}

\author{
Carsten Schradin, ${ }^{1,2, *}$ Michael Scantlebury, ${ }^{3,4}$ Neville Pillay, ${ }^{2}$ and Barbara König ${ }^{1}$ \\ 1. Institute of Zoology, University of Zurich, Winterthurerstr. 190, 8057 Zurich, Switzerland; 2. School of Animal, Plant, and \\ Environmental Sciences, University of the Witwatersrand, Private Bag 3, Wits 2050, Johannesburg, South Africa; 3. Quercus, School of \\ Biological Sciences, Queen's University Belfast, Belfast BT9 7BL, Northern Ireland; 4. Mammal Research Institute, Department of \\ Zoology and Entomology, University of Pretoria, Pretoria 0002, South Africa
}

Submitted May 17, 2008; Accepted September 30, 2008; Electronically published January 29, 2009

\begin{abstract}
AвSTRACT: The relative plasticity hypothesis predicts that alternative tactics are associated with changes in steroid hormone levels. In species with alternative male reproductive tactics, the highest androgen levels have usually been reported in dominant males. However, in sociable species, dominant males show amicable behaviors to gain access to females, which might conflict with high testosterone levels. We compared testosterone, corticosterone, and resting metabolic rate in male striped mice (Rhabdomys pumilio) following a conditional strategy with three different reproductive tactics: (i) philopatric group-living males, (ii) solitary-living roamers, (iii) dominant but sociable group-living territorial breeders. Philopatrics had the lowest testosterone but highest corticosterone levels, suggesting that they make the best of a bad job. Dominant territorial breeders had lower testosterone levels than roamers, which have a lower competitive status. Roamers had the highest testosterone levels, which might promote risky behavior, such as invading territories defended by territorial males. Roamers also had lower resting metabolic rates than either type of group-living males. Our results suggest that dominant males' testosterone levels reflect a trade-off between low testosterone amicable behavior and high testosterone dominance behavior.
\end{abstract}

Keywords: Rhabdomys, corticosterone, RMR, helper, group living, flexibility.

\section{Introduction}

Alternative male reproductive tactics have been described in a number of vertebrate taxa. Such an intraspecific polymorphism can be based either on frequency-dependent selection resulting in alternative tactics that yield the same

* Corresponding author; e-mail: carsten.schradin@zool.uzh.ch.

Am. Nat. 2009. Vol. 173, pp. 376-388. (C) 2009 by The University of Chicago. 0003-0147/2009/17303-50465\$15.00. All rights reserved.

DOI: $10.1086 / 596535$ fitness (Shuster and Wade 1991) or on individuals with low competitive status making the "best of a bad job" (based on status-dependent selection; Thornhill 1981; Gross 1996; Koprowski 2008; Taborsky et al. 2008). Within social vertebrates, tactics employed might include being a dominant territorial breeder, satellite, roamer, or helper (e.g., Reyer et al. 1986; Young et al. 2007; Scantlebury et al. 2008; Taborsky et al. 2008) and depend on the individual's assessment of the relative inclusive fitness gains given its current environmental, social, physical, and physiological status (Clutton-Brock 1989).

While some attention has been given to the ultimate (evolutionary) significance of alternative reproductive tactics (e.g., Sinervo et al. 2000; Tomkins and Brown 2004), less is known about the proximate (e.g., physiological) factors underlying these tactics (Gross 1996; Oliveira et al. 2008). Differences in display or fighting behavior may require substantial differences in energy investment between individuals following alternative tactics (e.g., Kenagy et al. 1989; Boonstra et al. 2001). In several bird species, the most dominant or sexually active individuals generally incur the greatest energy costs (reflected in elevated resting metabolic rates [RMRs]; Högstad 1987; Buchanan et al. 2001) and the highest circulating testosterone levels (Evans et al. 2000). These relationships are presumed to occur because reproductive superiority may necessitate increased "agonistic interactions with high overall activity levels that act to increase energy expenditures and the need for food" (Vézina and Thomas 2000, p. 231). In mammals, there is convincing evidence that physiology and energetics play a dominant role in alternative tactics (Koprowski 2008). For example, Damaraland mole rats pursue either infrequent worker or frequent worker tactics as determined by their level of energy expenditure (Scantlebury et al. 2006a). 
Steroid hormones are expected to contribute to the regulation of alternative male reproductive tactics as the nature of both avian and mammalian breeding systems is proximately regulated by temporal patterns of androgen secretion (Wingfield et al. 1990). Androgens may increase male aggression, mate attraction, and the frequency of mate searching and copulation but negatively affect parental care (Wingfield et al. 1990). Dominant breeders typically have higher testosterone levels than sneakers or satellites (Moore 1991; Moore et al. 1998; Sinervo et al. 2000; Wikelski et al. 2004; Oliveira et al. 2005; Knapp and Neff 2007). Most studies show a synchronous increase of energy expenditure and testosterone level (e.g., Buchanan et al. 2001), suggesting that increased reproductive activity is energetically costly (Gittleman and Thompson 1988). In comparison, glucocorticoids influence reproductive behavior by regulating the availability of energy by influencing glucogenesis and fat and protein metabolism (Reeder and Kramer 2005). These metabolic processes are reliable indicators of energetically demanding, stressful situations (Romero 2002; Reeder and Kramer 2005), but their influence on alternative reproductive behaviors and RMR remain unresolved (Buttemer et al. 1991). One suggestion is that in group-living animals, dominant individuals suppress the reproduction of subordinates by inducing chronic stress, resulting in sustained high levels of glucocorticoids in the subordinates: the "physiological castration" hypothesis (Reyer et al. 1986; Wingfield and Sapolsky 2003). However, it is not always the lower-ranking or subordinate individuals that have the highest glucocorticoid levels since the secretion of these hormones depends on whether high stress levels are a consequence of subordinate rank or a cost of dominance (Creel 2001; Romero 2002).

Moore (1991) proposed the relative plasticity hypothesis to explain the proximate regulation of alternative male reproductive tactics. According to this hypothesis, organizational (nonreversible) hormonal effects are expected to occur during early development when different tactics are fixed and yield the same average fitness. In contrast, activational (reversible) effects may occur in adults when different tactics yield different fitness payoffs, indicating a conditional strategy (Moore et al. 1998). In all fish and reptile species studied to date, dominant males show the highest level of aggression and the highest androgen levels (Moore 1991; Moore et al. 1998; Sinervo et al. 2000; Wikelski et al. 2004; Oliveira et al. 2005; Knapp and Neff 2007). In some group-living mammals, however, dominant males engage in amicable behaviors in which they court females by grooming them, sitting in body contact, or providing them with food (Stopka and Graciasova 2001; Schradin and Anzenberger 2003; Kutsakake and CluttonBrock 2006). This strategy might potentially be in conflict with aggressive high-testosterone behaviors, suggesting a trade-off between aggression and amicability in dominant group-living males. Concerning corticosterone, Moore et al. (1998) predicted that stress might play an important role when one tactic is inferior to another but not when different tactics yield identical fitness payoffs. Consequently, corticosterone levels will be increased in individuals that follow a best of a bad job tactic (Koprowski 2008).

In the Succulent Karoo, African striped mice (Rhabdomys pumilio) typically form extended family groups with one breeding male, up to four breeding females, and several adult philopatric males and females that do not breed in the group (Schradin and Pillay 2004b). Groups can contain up to 30 adult individuals of both sexes (Schradin and Pillay 2004b). Striped mouse males follow one of three tactics: (i) group-living philopatrics or (ii) solitary-living roamers that are thought to sneak copulations from females of communal groups that are defended by (iii) group-living amicable territorial breeders (Schradin and Pillay 2003, 2004b, 2005b; Schradin 2004). Males of all three tactics are thought to seek copulations with females, and preliminary results of genetic paternity analysis support that expectation, with the majority of offspring sired by territorial males (C. Schradin and A. Lindholm, unpublished data).

The three male tactics differ in caregiving behavior, with territorial breeders showing a high degree of paternal care (Schradin and Pillay 2003), philopatrics showing a corresponding degree of alloparental care (Schradin and Pillay $2004 b$ ), and roamers not engaging in any parental care (Schradin and Pillay 2005b). Territorial breeders initiate more amicable behaviors than other group members, and philopatrics often engage in amicable interactions, such as allogrooming or sitting in body contact (Schradin and Pillay 2004b). In contrast, roamers live solitarily and do not participate in amicable relationships. Therefore the striped mouse offers a useful opportunity to examine whether amicable dominant males (the territorial breeders) have lower testosterone levels than males of a subdominant, nonsocial, solitary-living tactic. If too high testosterone hinders amicability, territorial breeders would have intermediate levels, even if it is the most competitive, dominant tactic. Group-living philopatrics would have the lowest and solitary roamers the highest testosterone levels.

In this study, we explored the following question and predictions in a species exhibiting two group-living and one solitary-living tactic: (i) Is the observed behavioral polymorphism in male striped mice based on statusdependent selection (Gross 1996)? To answer this question we documented the reproductive tactics of individual males over the course of several breeding seasons. Thus, we aimed to quantify whether and how often males switched between tactics and whether switching was cor- 
related with body mass, an indicator of competitive ability (Schradin 2004). (ii) Circulating testosterone should differ between the alternative tactics, with lowest levels observed in philopatrics. If dominance status mainly depends on testosterone, territorial breeders will have the highest levels. If, however, high testosterone conflicts with amicable behavior, roamers are expected to have the highest levels. (iii) Corticosterone levels will be highest in philopatric males, which follow a best of a bad job tactic. They are expected to experience physiological stress as a consequence of being subdominant and due to high costs of dispersal forcing them to remain natal (Schradin 2005). (iv) Resting metabolic rate will be highest in territorial breeders, which are sexually active and defend a territory containing a group of communally breeding females.

\section{Material and Methods}

\section{Study Area and Period}

The study was conducted from 2005 to 2007 in Goegap Nature Reserve near Springbok in the Northern Cape Province, South Africa $\left(41.56^{\circ} \mathrm{S}, 1.60^{\circ} \mathrm{E}\right)$. Additional data for home ranges are included for 2002-2004. The area is arid, with an average rainfall of $160 \mathrm{~mm}$ per annum. The vegetation type is classified as Succulent Karoo (Cowling et al. 1999).

\section{Study Species}

Striped mice are diurnal, inhabit an open habitat, and are readily habituated to the presence of observers, which allows direct behavioral observations in the field (Schradin 2006). The breeding season of 3-4 months occurs in spring (two to three litters per female; Schradin and Pillay 2005a) and depends on rainfall. In our study, breeding took place from August to October in 2006 and from September to December during 2005 and 2007.

\section{Determination of Male Tactics}

Male striped mice may become sexually mature at 4-6 weeks of age, with a body mass of 20-30 g (Brooks 1982). In our study, only males with a body mass above $30 \mathrm{~g}$ and that were older than 6 weeks were considered. Male strategies were determined by a combination of trapping, behavioral observations, and radio tracking. Trapping was done around nesting sites at least 3 days per month as described in Schradin and Pillay (2004b). Trapped mice were weighed and sexed; males were recorded as scrotal (testes descended) or not (testes inside the body); and all mice were permanently marked with ear tags (National Band and Tag, Newport, KY) and hair dye (Rapido, Pine- town, South Africa) for individual recognition during behavioral observations (described in detail in Schradin and Pillay 2004b).

Home range sizes of 10 philopatric males, 39 territorialbreeding males, and 31 roaming males were collected during the six breeding seasons for 2002-2007 during September to November. All radio-tracked males were scrotal. Individuals were equipped with $\mathrm{MD}-2 \mathrm{C}$ radio transmitters (Holohil, Ontario, Canada) and radio tracked as described elsewhere (Schradin and Pillay 2005b) to determine home ranges and sleeping sites. Home ranges were determined as $95 \%$ minimum convex polygons in the program Ranges 6 for best comparison with previous studies (Schradin and Pillay $2004 b, 2005 b$ ).

We classified males as philopatric if they had previously been trapped as juveniles $(<30 \mathrm{~g})$ and were observed during the study as adults at the same group. Roaming males were classified as adult males that did not share nesting sites with any other mice. Territorial-breeding males were adult males that lived in groups other than their natal groups. The last were always the heaviest males of the groups, and each communal group had only one territorial-breeding male (see "Results").

\section{Blood Collection}

Blood samples for this study were collected during the 2005-2007 breeding seasons during August to November. Mice were trapped at their nests during the morning shortly after they became active, controlling for possible circadian rhythms of hormone release. Traps were watched from a distance of $10 \mathrm{~m}$. As soon as a male entered a trap, he was removed and anesthetized with diethyl ether (validated in Schradin 2008b), a blood sample was taken from the retro-orbital sinus (without any damage to the eye; Schradin and Pillay 2004a), and the body mass, identification (ID), and whether the male was scrotal were noted. Using this protocol, samples could be collected within 1.53 min after a mouse entered a trap, which did not influence basal corticosterone levels (see "Results"). Additional traps were set at a second nest and striped mice were sampled 45 min later, which meant that individuals would have spent up to $45 \mathrm{~min}$ in the traps before being sampled. This was done to obtain further samples for testosterone (but not corticosterone) measurements; testosterone values are not influenced by this trapping procedure (Schradin 2008b and "Results"). Blood samples were left at room temperature for $1.5 \mathrm{~h}$ (indoor temperatures below $20^{\circ} \mathrm{C}$ ) to clot and then centrifuged for 10 min to obtain serum for analysis. 


\section{Hormone Assays}

All samples were analyzed in the EIA (Enzyme Immunoassy) laboratory of the Zoological Institute, University of Zurich. Commercial kits from IBL (Immuno Biological Laboratories) Hamburg were used for corticosterone and testosterone. We followed the procedures listed in the manuals of the kits, but due to very high corticosterone levels, samples were diluted $1: 50$ or $1: 100$. In some cases, the available sample volume for testosterone measurements was too small and had to be diluted 1:1 with the zero standard. Inter- and intra-assay variability was measured with pools from striped mouse serum left over from samples used for this study. Three pools were used to determine interassay variability for testosterone (pool 1: 12.8\%, $N=7$; pool 2: 19.1\%, $N=4$; pool 3: 7.3\%, $N=4$ ), and two of them were also used for intra-assay variability (pool 1: $9.9 \%, N=8$; pool 2: $6.9 \%, N=8$ ). Two pools were used to determine interassay variability for corticosterone (pool 1: 15.8\%, $N=12$; pool 2: $14.4 \%, N=12$ ), and one of these pools was used to determine intra-assay variability (pool 1: 8.0\%, $N=8$ ).

\section{RMR Measurements}

In October 2006, we determined RMR of seven philopatric males, 10 roaming males, and 10 territorial-breeding males. No blood samples were taken from these males on the days when RMR measurements were taken to avoid an influence of stress on RMR; RMR was determined as the minimal oxygen consumption $\left(\mathrm{mL} \mathrm{O}_{2} / \mathrm{h}\right)$, as described in detail by Scantlebury et al. (2006b). In brief, we used an open circuit respirometry system with a $1,610-\mathrm{cm}^{3}$ metabolic chamber set at $31.0^{\circ} \pm 0.5^{\circ} \mathrm{C}$, which is within the thermoneutral zone of this species (Scantlebury et al. $2006 b$ ). Dried air was pumped into the chamber at a rate of $500 \mathrm{~mL} / \mathrm{min}$, and depressions in oxygen concentration were $0.25 \%-0.4 \%$. Readings were taken every $30 \mathrm{~s}$ for 20 min after an initial hour, when animals were accustomed to the chamber (Bennett et al. 1992). The mean of the lowest 10 readings of oxygen consumption $\left(\mathrm{mL} \mathrm{O}_{2} / \mathrm{h}\right)$ was taken as RMR when animals were seen to be at rest.

\section{Data Analysis and Statistics}

The software packages Instat 3.05 and SAS 9.1.3 were used. Data are presented as mean $\pm \mathrm{SD}$. Correlations were done using Spearman correlations coefficient $r_{s}$. General linear mixed models (GLMM) were fitted to normal data using restricted maximum likelihood (SAS, procedure MIXED). In all GLMMs, residuals were accepted as being normally distributed when Shapiro-Wilk statistics yielded $P>.05$. Error degrees of freedom (df) were calculated using the
Satterthwaite method. Effects were tested using Type III (simultaneous) modeling; that is, in multiple effects models, parameters for each independent variable were corrected for all other fixed effects in the model. Differences between the least squares means (function LSMEANS in SAS) of multiple categories were compared post hoc using $t$-tests, and all $P$-values stated are given after a TukeyKramer adjustment for multiple comparisons.

For each male trapped at the beginning of a breeding season (October 2005, $N=67$; September 2006, $N=$ 27; and September 2007, $N=16$ ), we determined its current, previous, and next tactic. This could not be determined for every male, as many philopatrics disappeared (either due to mortality or dispersal; table 1), and several roaming and territorial-breeding males immigrated into the study area from elsewhere, so that we did not know their previous tactic. For each male, its month of birth was estimated from body mass at the first trapping event, using a population-specific growth curve available from 7 years of field studies (C. Schradin, unpublished data).

For comparison between body mass and age of males using the three different tactics, we used data collected during the first month of the breeding season. Body mass and age were compared between the three tactics at the start of the 2005-2007 breeding seasons using two GLMMs with year as a random effect. Age data were log transformed to meet the criterion of a normal distribution. The tactic for each male was determined every month. If a male switched from the tactic it had followed at the start of the breeding season to another tactic, we compared its age and body mass in the month when it changed tactics with its original age and body mass at the beginning of the breeding season.

Home range data were analyzed using a GLMM in which the observed tactic (philopatric, roamer, or territorial breeder) was a fixed effect and year a random effect. Home range data were log transformed before analysis to meet the criterion of normality.

To explain corticosterone and testosterone levels, GLMMs were fitted to the data set. Tactic, whether males were scrotal, whether males carried a transmitter, and whether traps were watched (and checked immediately) or checked 45 min after they were set (only for testosterone) were entered as fixed categorical effects into the model. The time it took to take the blood sample (in seconds), body mass (in grams), and age (in months) were entered as covariates into the model. Year was included as random factor. Hormone data were log transformed before analysis. The current data include samples used for another study (Schradin 2008b) and additional data collected over 2007, as well as data for roaming males. For basal corticosterone, we had 62 blood samples from 54 individuals. For testosterone, we had 134 blood samples from 100 in- 
Table 1: Number of male striped mice that switched reproductive tactics at any time during the breeding season

\begin{tabular}{|c|c|c|c|c|c|}
\hline From & To & 2005 & 2006 & 2007 & Total \\
\hline Juvenile & Territorial breeder & 0 & 0 & 0 & 0 \\
\hline Juvenile & Roamer & 0 & 0 & 0 & $0^{\mathrm{a}}$ \\
\hline Juvenile & Philopatric & 47 & 5 & 0 & 52 \\
\hline Total juveniles & & & & & 52 \\
\hline Philopatric & Roamer & 7 & 7 & 5 & 19 \\
\hline Philopatric & Territorial breeder & 9 & 9 & 6 & 24 \\
\hline Philopatric & Disappeared & 37 & 4 & 0 & 41 \\
\hline Total philopatrics ${ }^{\mathrm{b}}$ & & & & & 84 \\
\hline Roamer & Territorial breeder & 3 & 6 & 3 & 12 \\
\hline Roamer & Philopatric & 0 & 0 & 0 & 0 \\
\hline Roamer & Disappeared & 9 & 5 & 6 & 20 \\
\hline Total roamers ${ }^{\mathrm{b}}$ & & & & & 32 \\
\hline Territorial breeder & Philopatric & 0 & 0 & 0 & 0 \\
\hline Territorial breeder & Roamer & 0 & 0 & 0 & 0 \\
\hline Territorial breeder & Disappeared & 10 & 12 & 7 & 29 \\
\hline Total territorial breeders ${ }^{\mathrm{b}}$ & & & & & 29 \\
\hline
\end{tabular}

Note: Data for adult males at the start of the 2005-2007 breeding seasons. Data for juvenile males were obtained post hoc by examining the previous tactic used by philopatrics, roamers, and territorial breeders at the start of the breeding season.

a Juvenile males becoming roamers when reaching adulthood are regularly observed in grassland populations of striped mice (Perrin 1980; Schradin 2005; Schradin and Pillay 2005b) but were not observed in our study.

b Seven males that switched from philopatric to roamer to territorial breeder are included for all three tactics; 10 males switched from philopatric to roamer before disappearing and are included for both philopatrics and roamers; 16 males that switched from philopatric to territorial breeder and then disappeared are included for both philopatrics and territorial breeders; six males that switched from roamer to territorial breeder and then disappeared are included for both roamers and territorial breeders.

dividuals. The sample size in this study was based on the total number of individuals sampled. If an individual was sampled repeatedly within the same variable (social tactic, scrotality, carrying a transmitter or not), we used the mean per individual (nine individuals for testosterone and four individuals for corticosterone). In all other cases, we only used the last measurement per individual and discarded all others (14 individuals for testosterone and four individuals for corticosterone). We used the last instead of the first sample because individuals were often measured first as philopatric, the class for which we already had more samples than for roamers and territorial breeders. If we had chosen to use the first sample only, to discard all data from males with several measurements, or to use all samples and use individual ID as a random factor, statistical results would have been the same, which means our results were robust with respect to data point selection.

\section{Results}

\section{Differences in Home Range Size, Body Mass, and Age between Males Following the Three Tactics}

Males of the three tactics differed significantly in their measured home range size $(F=12.65$, $\mathrm{df}=2,73.9, P<$ .0001 ; fig. 1). Philopatric males had significantly smaller home ranges than roaming males $(t=-4.64$, $\mathrm{df}=74.7$,
$P<.0001)$, and there was a nonsignificant trend indicating that home ranges were smaller than those of territorialbreeding males $(t=-2.26, \mathrm{df}=72.6, P=.068)$. Roamers had significantly larger home ranges than territorial breeders $(t=-4.09$, df $=74.9, P=.0003)$.

At the start of the breeding season, philopatrics were more likely to be nonscrotal than either roamers or territorial breeders ( 15 of 52 philopatric males were nonscrotal, while all 29 roamers and all 29 territorial breeders we handled were scrotal; $P=.0007$, Fisher's Exact Test, for both comparisons). Scrotal philopatrics were significantly heavier than nonscrotal philopatrics $(40.1 \pm 6.9 \mathrm{~g}$, $N=37$ vs. $32.7 \pm 1.9 \mathrm{~g}, N=15 ; t=4.02$, df $=50$, $P=.0002$ ).

Males of the three tactics differed significantly in body mass at the beginning of the breeding season $(F=75.16$, $\mathrm{df}=2,107, P<.0001$; fig. $2 A)$. Philopatric males $(38.0 \pm$ $6.8 \mathrm{~g}$ ) were significantly lighter than both territorial-breeding males $(60.7 \pm 6.8 \mathrm{~g} ; t=-12.19, \mathrm{df}=106, \quad P<$ $.0001)$ and roaming males $(52.2 \pm 7.1 \mathrm{~g} ; t=-7.30$, $\mathrm{df}=106, P<.0001)$, and roaming males were significantly lighter than territorial-breeding males $(t=4.85$, df $=105, P<.0001)$.

Males of the three tactics differed significantly in age at the beginning of the breeding season $(F=27.30$, $\mathrm{df}=$ $2,106, P<.0001)$. Philopatric males $(3.9 \pm 1.9$ months $)$ 


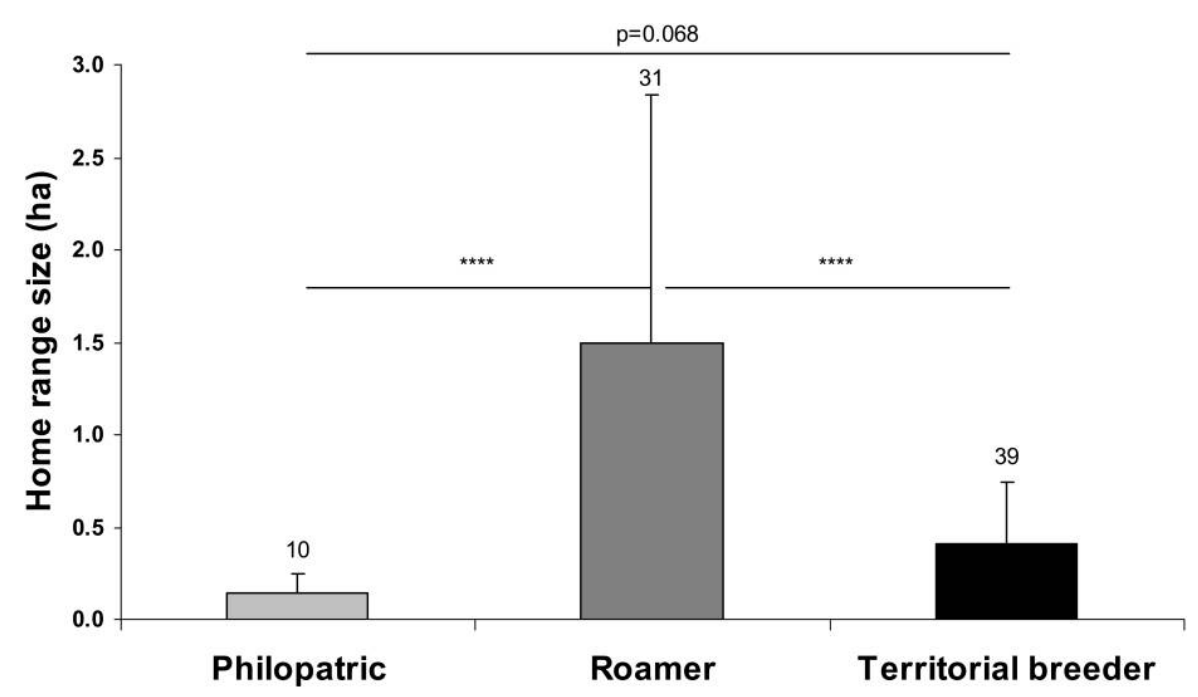

Figure 1: Home range sizes of philopatric, roaming, and territorial-breeding striped mouse males. Mean \pm SD; sample sizes are provided above bars. Four asterisks, $P<.0001$.

were significantly younger than both roaming males $(8.4 \pm 2.9$ months; $t=-5.14, \mathrm{df}=107, P \leq .0001)$ and territorial-breeding males (10.4 \pm 2.7 months; $t=-7.20$, $\mathrm{df}=107, P<.0001)$. Roaming males did not differ significantly from territorial-breeding males $(t=2.04, \mathrm{df}=$ $105, P=.11$ ).

A GLMM with tactic as the response variable could not determine whether age or body mass was more important in predicting the tactic, as both were significant (body mass: $F=21.24, \mathrm{df}=1,105, P<.0001$; age: $F=15.70$, $\mathrm{df}=1,59.3, P=.0002)$, as was their interaction $(F=$ 11.77, $\mathrm{df}=1,100, P=.0009$ ).

\section{Tactic Switching}

We never observed juveniles becoming roamers or territorial breeders without first becoming adult philopatrics (table 1). Philopatric males either disappeared (49\%; presumably due to predation or by emigrating into areas outside the study area) or became roamers (23\%) or territorial breeders (28\%; table 1). Roamers either disappeared (63\%) or became territorial breeders ( $37 \%$; table 1$)$. All territorial breeders (100\%) disappeared without being observed to change their tactics (table 1), although two territorial breeders changed groups before disappearing.

Males switching from philopatric to roamer were significantly lighter than males changing from philopatric to territorial breeder $(48.1 \pm 7.7 \mathrm{~g}$ vs. $59.5 \pm 6.6 \mathrm{~g}$; $t=$ 5.99, $\mathrm{df}=66, P<.001)$. Philopatric males that became roamers were significantly lighter than roaming males that became territorial breeders $(48.1 \pm 7.7 \mathrm{~g}$ vs. $60.9 \pm 5.2 \mathrm{~g}$; $t=-5.88, \mathrm{df}=66, P<.0001)$. However, philopatric males that became territorial breeders did not differ in body mass from roaming males that became territorial breeders $(59.5 \pm 6.6 \mathrm{~g}$ vs. $60.9 \pm 5.2 \mathrm{~g} ; t=-0.61$, $\mathrm{df}=66, P=.82)$.

Males differed significantly in age when switching from one tactic to another, depending on their previous and subsequent tactics $(F=19.45, \mathrm{df}=2,63, P<.0001)$. Philopatric males that became roamers were significantly younger than philopatric males that became territorial breeders $(7.4 \pm 2.6$ months vs. $10.1 \pm 1.7$ months; $t=$ 4.34, $\mathrm{df}=63, P<.0002)$. Philopatric males that became roamers were significantly younger than roaming males that became territorial breeders $(7.4 \pm 2.6$ months vs. $11.8 \pm 2.4$ months; $t=-5.67, \mathrm{df}=63, P<.0001)$. However, philopatric males that became territorial breeders did not differ from roaming males that became territorial breeders $(10.1 \pm 1.7$ months vs. $11.8 \pm 2.4$ months; $t=$ -1.99 , df $=63, P=.12)$.

\section{Hormonal Differences between Male Tactics}

Nonscrotal philopatrics $(N=38)$ did not differ significantly in testosterone levels $(0.46 \pm 0.3 \mathrm{ng} / \mathrm{mL})$ from scrotal philopatrics $(0.40 \pm 0.3 \mathrm{ng} / \mathrm{mL}, N=23 ; t=0.68$, $\mathrm{df}=59, P=.50)$. Thus, we pooled scrotal and nonscrotal males for all following analyses, including scrotality as a covariate. Serum testosterone levels were not significantly influenced by body mass $(F=0.55$, df $=1,48.9, P=$ $.46)$, age of individual $(F=0.18, \mathrm{df}=1,46.5, P=.67)$, method of sampling (whether traps were emptied imme- 

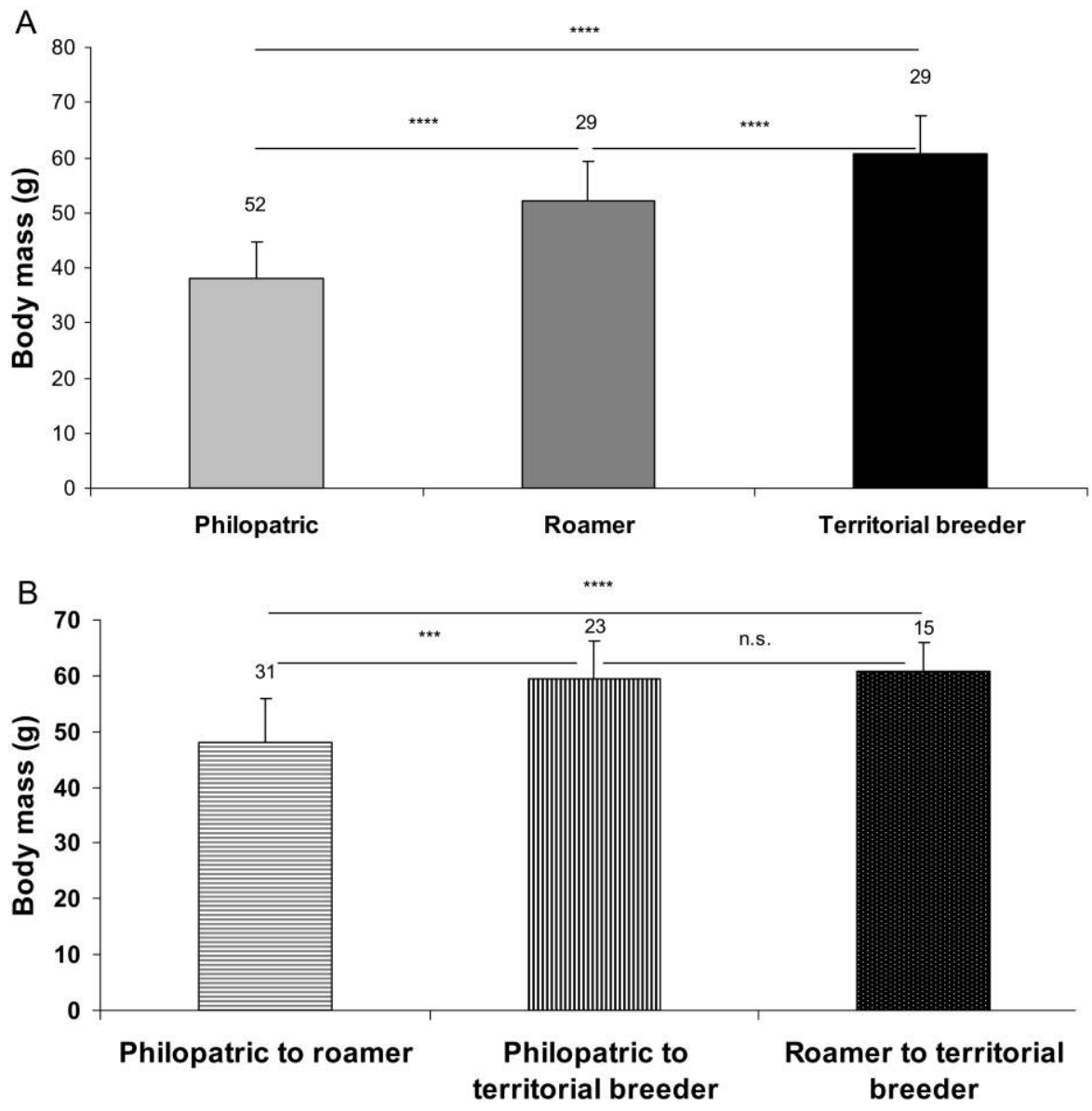

Figure 2: Body mass of $(A)$ philopatric, roamer, and territorial-breeding males at the start of the breeding season and $(B)$ when males switched tactic at any time during the breeding season. Mean $\pm \mathrm{SD}$; sample sizes are provided above bars. n.s., not significant; three asterisks, $P<.001 ;$ four asterisks, $P<.0001$.

diately after capture or checked after $45 \min ; F=0.22$, $\mathrm{df}=1,43.9, P=.63)$, time needed to take the blood sample $(F=0.36, \mathrm{df}=1,48.3, P=.55)$, whether males were scrotal $(F=0.02, \mathrm{df}=1,48.5, P=.8)$, and whether mice were carrying a transmitter $(F=0.63, \mathrm{df}=1,47.1, P=$ .43). The only significant factor was tactic $(F=25.49$, $\mathrm{df}=2,47.7, P<.0001)$. Stepwise exclusion of nonsignificant effects confirmed these findings, with tactic remaining as the only significant factor $(F=41.29, \mathrm{df}=2,55.0$, $P<.0001)$. Philopatric males had lower testosterone levels than both roamers $(t=-8.74, \mathrm{df}=55.0, P<.0001)$ and territorial breeders $(t=-2.67, \mathrm{df}=55.0, P=.02)$, while roamers had significantly higher testosterone levels than territorial breeders $(t=-6.16, \mathrm{df}=55.0, P<.0001$; fig. $3 A)$.

Basal corticosterone levels were not significantly influenced by age of the individual $(F=0.09, \mathrm{df}=1,36.9$, $P=.76)$, time needed to take the blood sample $(F=$ 0.72 , df $=1,36.2, P=.40)$, whether males were scrotal
$(F=1.55, \mathrm{df}=1,35.1, P=.22)$, and whether mice were carrying a transmitter $(F=2.20, \mathrm{df}=1,35.9, P=.15)$. The only two significant factors influencing corticosterone were body mass ( $F=5.26$, $\mathrm{df}=1,37.0, P=.03)$ and tactic $(F=3.31, \mathrm{df}=2,35.6, P=.048)$. Stepwise exclusion of nonsignificant effects confirmed these findings, with body mass $(F=8.46, \mathrm{df}=1,40.9, P=.006)$ and tactic being significant $(F=10.79, \mathrm{df}=2,40.8, P=.0002)$. Heavier males had lower corticosterone levels $\left(r_{\mathrm{s}}=-0.73, N=\right.$ $54, P<.0001)$. Philopatrics had higher mass-independent corticosterone levels than both roamers $(t=4.64, \mathrm{df}=$ $41, P<.0001)$ and territorial breeders $(t=3.33, \mathrm{df}=41$, $P=.005)$, while roamers and territorial breeders did not differ significantly $(t=1.17, \mathrm{df}=40.3, P=.48$; fig. $3 B)$.

\section{Resting Metabolic Rate}

Mean absolute values of RMR for philopatrics, roamers, and territorial breeders were $45.7 \pm 8.8 \mathrm{~kJ} /$ day, $49.5 \pm$ 

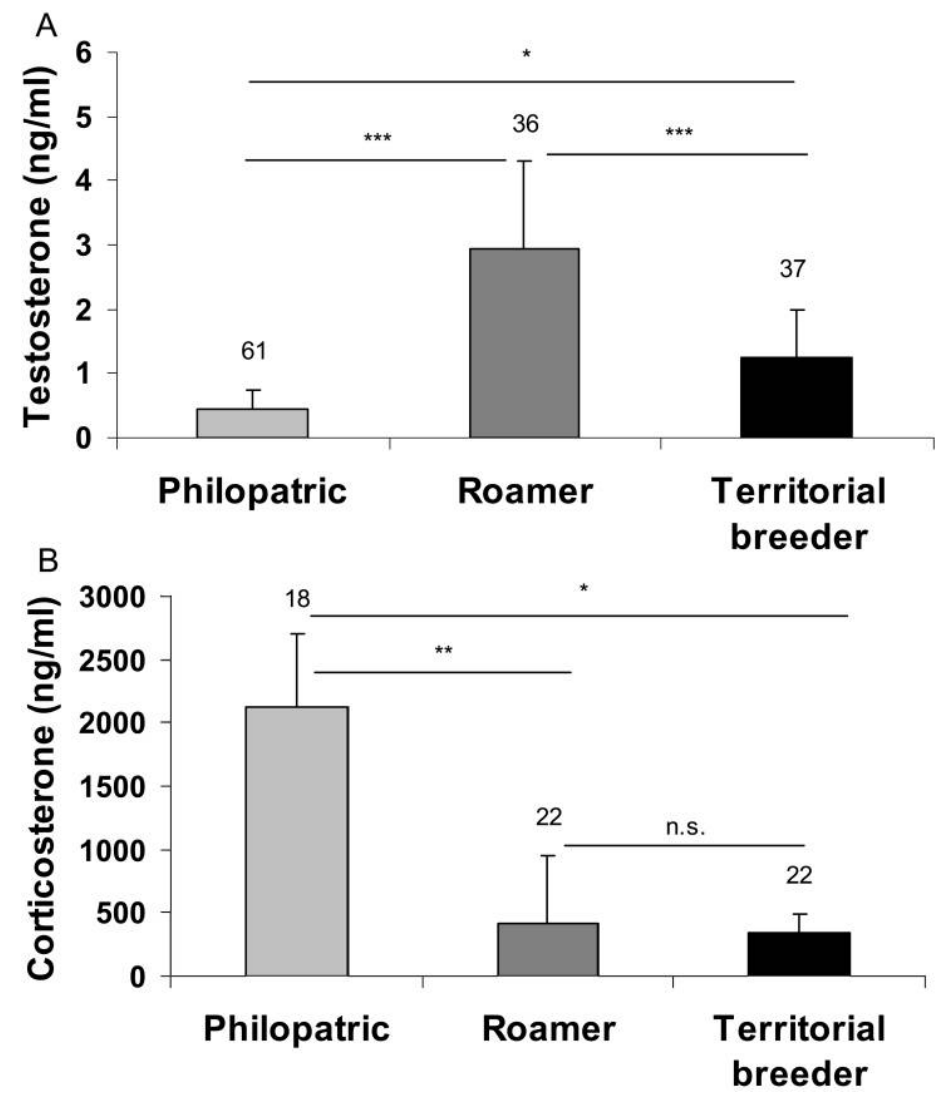

Figure 3: Comparisons of steroid hormone levels between philopatric, roamer, and territorial-breeding males. $A$, Testosterone levels; $B$, basal corticosterone levels. Mean $\pm \mathrm{SD}$; sample sizes are provided above bars. n.s., not significant; one asterisk, $P<.05$; two asterisks, $P<.01 ;$ three asterisks, $P<.001$.

$8.6 \mathrm{~kJ} /$ day, and $75.5 \pm 15.0 \mathrm{~kJ} /$ day. There were significant differences in RMR between males following different tactics (ANCOVA; $F=10.26$, df $=2,23, P=.001$ ). However, there was no significant interaction between body mass and tactic (breeder/roamer/philopatric) on RMR (ANCOVA; $F=0.14$, $\mathrm{df}=2,21, P=.87$ ), suggesting that the relationship between RMR and body mass was similar for all males. Post hoc tests revealed that there was no significant difference in RMR between territorial breeders and philopatric males but that roamers had significantly lower RMR than both territorial breeders $(P<.01)$ and philopatric males $(P<.05$; fig. 4$)$. The least squares fitted regressions for RMR against body mass were as follows: territorial breeders $\left(r^{2}=0.43 ; F=6.03, \mathrm{df}=1,8\right.$, $P=.04)$,

$$
\operatorname{RMR}(\mathrm{kJ} / \text { day })=1.9+1.22 \times \text { body mass }(\mathrm{g}) \text {; }
$$

roamers $\left(r^{2}=0.84 ; F=42.41, \mathrm{df}=1,8, P<.001\right)$,

$$
\operatorname{RMR}(\mathrm{kJ} / \text { day })=-0.25+0.96 \times \text { body mass }(\mathrm{g}) \text {; }
$$

and philopatrics $\left(r^{2}=0.43 ; F=3.76, \mathrm{df}=1,5, P=\right.$ $.11)$,

$$
\operatorname{RMR}(\mathrm{kJ} / \text { day })=5.3+1.06 \times \text { body mass }(\mathrm{g}) .
$$

Resting metabolic rates and hormonal data were available for five territorial breeders and four roamers (but no philopatrics). There was no significant positive correlation between RMR and corticosterone $\left(r_{\mathrm{s}}=-0.67, N=8\right.$, $P=.08)$ or between RMR and testosterone $\left(r_{\mathrm{s}}=0.17\right.$, $N=9, P=.68)$.

\section{Discussion}

Male striped mice in the Succulent Karoo begin adult life as philopatrics and can later switch to being roamers or territorial breeders. Tactic change depends on their body mass, which in turn correlates with their success in territorial encounters (Schradin 2004). Different tactics are associated with differences in steroid hormone levels (fig. $5)$, which is in accordance with the relative plasticity hy- 


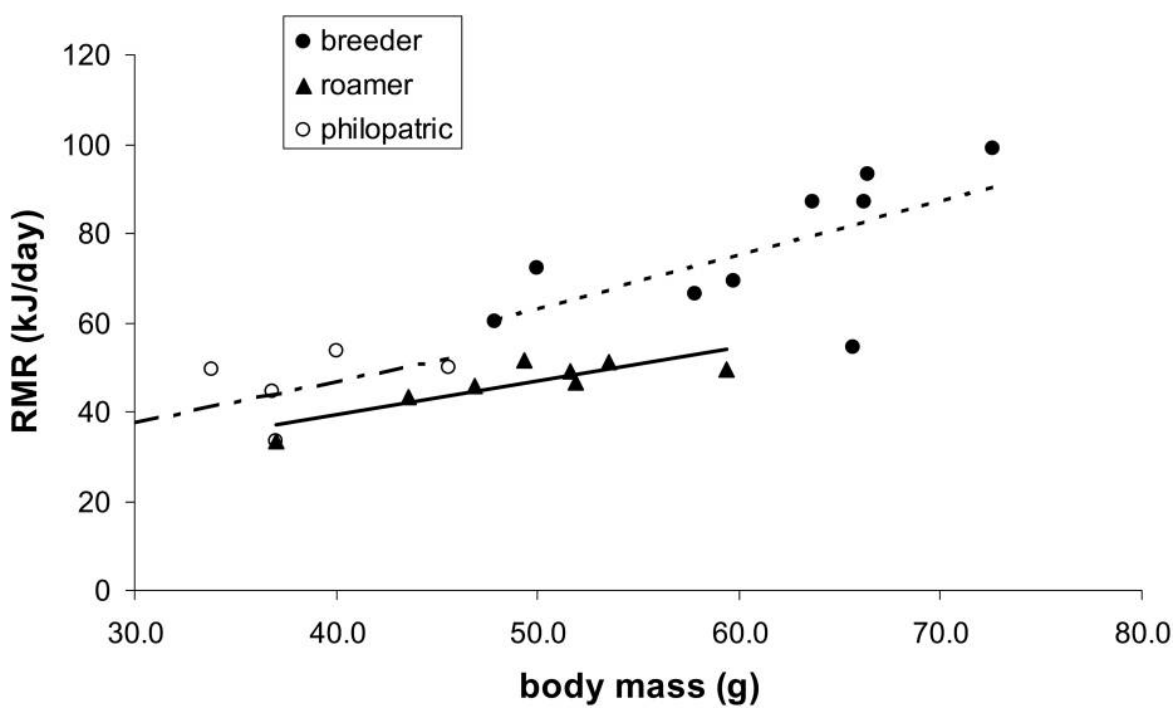

Figure 4: Relationship between resting metabolic rate (RMR; kJ/day) and body mass ( $\mathrm{g}$ ) of philopatric, roaming, and territorial-breeding males (open circles, triangles, and filled circles, respectively).

pothesis proposed by Moore (1991). However, in contrast to previous studies on fish and reptiles (e.g., Wikelski et al. 2004; Oliveira et al. 2005), it is not the large dominant males but solitary roaming males that have the highest testosterone levels, suggesting that testosterone levels depend not entirely on status but also on the social tactic employed.

\section{A Conditional Strategy with Three Tactics}

Male striped mice follow a conditional strategy, which means that adults can change their tactic depending on their status (Gross 1996). Status depends on body mass, which to some extent correlates positively with age during the breeding season but also decreases with age in the dry season (Schradin and Pillay 2005a). The competitive and social status is likely to be maintained by aggressive interactions as heavier individuals are more likely to attack lighter individuals than vice versa (Schradin 2004). Young males of low body mass remain philopatric in their natal group. With increasing body mass, they change to either roamers or territorial breeders, with the switch to territorial breeders occurring at a higher body mass than that to roamers. Roamers occur only during the breeding season, not during the nonbreeding season, when they either disappear or become group living by associating with a single breeding female and her philopatric offspring (C. Schradin, unpublished data). During the nonbreeding season, philopatrics never become solitary roamers but benefit from group living (Schradin 2005; Scantlebury et al. $2006 b$ ). Thus, the body mass of philopatrics at the start of the breeding season (and not during the dry nonbreeding season) predicts whether they remain philopatric, switch to roaming, or switch to becoming territorial breeders.

Mice were never observed to revert to roaming once attaining a territorial-breeding status, although on two occasions breeders switched their groups. Theoretically, it may pay to revert to roaming if the fitness payoffs were greater (e.g., if the number of breeding females in a group decreases by predation). A short breeding season (2-3 months) and low mortality (Schradin and Pillay 2005a) might make such a scenario unlikely. When male striped mice in grassland populations reach adulthood, they become roamers without first being adult philopatrics, and territorial breeders do not occur in this population (Perrin 1980; Schradin 2005; Schradin and Pillay 2005b; fig. 5). In grasslands, striped mice live solitarily, and solitary breeding females are visited by roaming males (Schradin 2005). Thus, the philopatric tactic is not obligate for male striped mice.

Territorial-breeding males defend their harems from other males, while roamers seem to follow a sneaker tactic. Philopatric males might also gain mating opportunities, as described for other species with subdominant male helpers (Double and Cockburn 2003; Young et al. 2007). Home ranges of philopatric male striped mice overlap with those of females from neighboring groups (Schradin and Pillay 2004b), and breeding females meet philopatric males from other groups during foraging (Schradin 2006). Our results predict that territorial breeders have the highest and philopatrics the lowest fitness, with roamers occupying an intermediate position (preliminary support exists for 


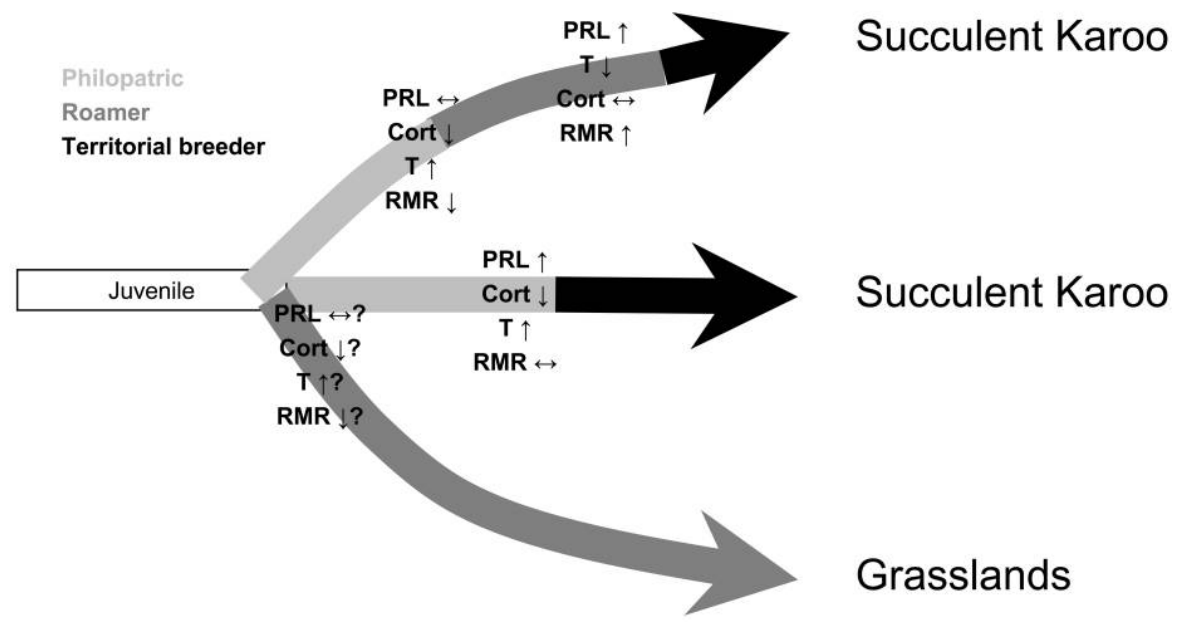

Figure 5: Alternative male reproductive tactics in striped mice and correlated physiological changes. Light gray = philopatrics; dark gray = roamers; black = territorial breeders; $P R L=$ prolactin; $T=$ testosterone; Cort = corticosterone; $R M R=$ resting metabolic rate; downward arrow $=$ decrease; upward arrow = increase; horizontal double arrow = stays the same; question mark = predicted change. When reaching adulthood, male striped mice in the Succulent Karoo remain philopatric in their natal nest (top and middle arrows). Philopatrics can become roamers first (top arrow), which is associated with an increase in testosterone and a decrease in corticosterone and RMR, before becoming territorial breeders and experiencing an increase in prolactin (Schradin 2008a) and RMR and a decrease in testosterone. Philopatrics can also directly become territorial breeders (middle arrow), which is associated with a decrease in corticosterone and an increase in testosterone and prolactin (Schradin 2008a). The situation in the grassland striped mouse population is provided for comparison (bottom arrow; Schradin and Pillay 2005b): males become and remain roamers, which is predicted to be associated with an increase in testosterone and a decrease in corticosterone and RMR.

this prediction for 1 year; C. Schradin and A. Lindholm, unpublished data).

\section{Differences in Hormone Levels and the Relative Plasticity Hypothesis}

Our results are in agreement with the relative plasticity hypothesis (see fig. 5), which states that changes in behavioral phenotypes during adulthood are regulated by hormones (Moore et al. 1998). It is known that in species with alternative male reproductive tactics, the dominant males are most aggressive and have the highest androgen levels (Moore et al. 1998; Wikelski et al. 2004; Oliveira et al. 2005, 2008; Knapp and Neff 2007). However, in sociable species, high testosterone levels might not be compatible with high levels of amicable behavior (Wingfield et al. 1990). Thus, a trade-off between amicable and dominance behavior, both part of the tactic of the territorial breeders, was predicted to be represented by intermediate testosterone levels. Territorial breeders with the highest competitive status have three times higher testosterone levels than philopatrics with the lowest status. However, territorial breeders have testosterone levels only half as high as those of roamers, which have a lower status than territorial breeders. This supports our hypothesis that testosterone levels of territorial breeders but not of solitary- living roamers reflect a trade-off between aggressive and amicable behaviors.

Why do roamers have the highest testosterone levels? Roamers might benefit from the anxiolytic (fear-reducing) effect of high testosterone levels (Aikey et al. 2002; Vermeersch et al. 2008). Roamers have 10 times larger home ranges than philopatrics and more than three times larger home ranges than territorial breeders, overlapping the home ranges of several groups. Roamer males invade the home ranges of several female groups defended by heavier breeding males and even by smaller philopatric males (Schradin 2004). If roamers engage more often in aggressive male-male interactions, their high testosterone levels could also be explained by the challenge hypothesis, which predicts that testosterone levels increase as a result of aggressive interactions between males (Wingfield et al. 1990). However, this is unlikely in our case, as males were trapped during the morning shortly after they left their nests and thus probably before interactions with other mice had occurred. Therefore, differences in testosterone levels might be explained by differences in the social tactic, differences in caregiving behavior, reproductive suppression in philopatrics, and risk-prone behavior in roamers.

Corticosterone levels, however, are seven times higher in philopatrics than in territorial breeders or roamers. This suggests that philopatric males are physiologically stressed, 
which could be one reason for their low testosterone levels (Creel 2001; Young et al. 2006; Scantlebury et al. 2008). Chronically increased glucocorticoid levels indicate allostatic load, that is, physiological costs due to an overactivation of the neuroendocrine stress response (McEwen 1999). Strategies to cope with this would be to down regulate glucocorticoid receptors or to behaviorally avoid the situation leading to chronically increased glucocorticoid levels. This supports our interpretation that being a philopatric male is making the best of a bad job (Moore et al. 1998). As a consequence, philopatric males should leave their natal groups as soon as another tactic becomes more appropriate for them, that is, when costs of dispersing to become roamers or territorial breeders are lower than costs of remaining philopatrics. It is likely that philopatric males would become territorial breeders if free territories were available (Schradin 2005). Importantly, about $75 \%$ of philopatric males at the start of the breeding season were scrotal and thus probably physiologically able to breed, despite their low testosterone levels. In captivity, adult males kept in their family groups have low testosterone levels but when paired with an unfamiliar female can breed immediately and have viable sperm, although much less than breeders (C. Schradin, unpublished data).

\section{Differences in RMR}

In support of our prediction, territorial breeders have the highest absolute RMR values, but this was only because they are the largest individuals. When body mass is taken into account, breeders have similar RMR values to those of philopatric males, whereas roamers have lower values than those of either breeders or philopatric males. Interestingly, the relationship between RMR and corticosterone level marginally failed to reach significance $(P=.08)$, with low RMR values tending to be associated with higher corticosterone levels. This is inconsistent with the prediction that high stress hormone levels cause high RMR. Whether this relationship is biologically relevant is unclear as the current sample size is low. By comparison, no relationship between RMR and testosterone is evident. Thus, RMR values obtained in these mice are complex and more likely depend on a variety of factors. Elevated RMR values are often associated with a higher reproductive and social status (Buchanan et al. 2001), possibly as a consequence of mate searching and acquisition, as well as mating (Gittleman and Thompson 1988). In our study, roamers have lower values than both territorial breeders and philopatrics. This is consistent with our prediction that high RMR values should occur in territorial-breeding males but raises the question of why values were similarly high in philopatrics. One possibility is a compensatory mechanism. In a recent study on the same population, energy expenditure was greater in individuals from smaller groups, probably due to thermoregulatory benefits of huddling in larger groups (Scantlebury et al. 2006b). The implications of these results are that solitary roamers are expected to have larger thermoregulatory costs at night than group-living philopatrics or territorial breeders. If roamers do expend more energy at night, they might then need to reduce energy expenditure in other aspects of their energy budget-such as RMR. Evidence of such energy compensation has been shown in zebra finches Taeniopygia guttata and starlings Sturnus vulgaris (Deerenberg et al. 1998) as well as in laboratory mice (e.g., Hambly and Speakman 2005). Hence, energy conservation due to huddling might enable both territorial breeders and philopatrics to sustain a higher RMR, allowing them to achieve a higher maximal rate of energy expenditure (Hammond and Diamond 1997; Speakman et al. 2004), which is potentially advantageous in dealing with predator encounters and territorial disputes with conspecifics. Roamers might not be able to increase their RMR and thus obtain the associated benefits because of their extra energy expenditure due to solitary sleeping.

\section{Conclusions}

Male striped mice following different reproductive tactics in a conditional strategy differ in steroid hormone levels (this study) and in peptide hormone levels (Schradin $2008 a$ ). However, in contrast to the results of previous studies with other species, we found that dominant males have lower testosterone levels than males of a lower status (roamers). This suggests a possible trade-off between amicable and aggressive behaviors. Corticosterone levels are almost an order of magnitude higher in philopatric males than in roamers or territorial breeders. This suggests that philopatrics are making the best of a bad job, being forced to remain philopatric due to high population density, and that they would disperse when given the opportunity (Schradin 2005). Surprisingly, RMR values are similar for territorial breeders and philopatric males but lower in roamers. It is unclear why this is the case, but some form of an energetic compensatory mechanism might be occurring because roamers are expected to have the highest thermoregulatory costs at night.

\section{Acknowledgments}

We are thankful for the support by the Department of Tourism, Environment, and Conservation of the Northern Cape and the support by Goegap Nature Reserve. This study was supported by the Holcim Foundation (Switzerland), the Vontobel Foundation (Switzerland), the Swiss National Science Foundation (3100A0-120194), the Claude Leon Foun- 
dation (South Africa), the University of the Witwatersrand, and the University of Zurich. N. Bennett (University of Pretoria, South Africa) kindly provided the respirometry equipment. We would like to thank the Northern Cape Department of Agriculture, Land Reform, and Environment for their assistance and the staff at Goegap Nature Reserve. We are grateful to students who assisted in collecting data over the years. K. Morrison helped to correct the English. The study received clearance from the animal ethics committee of the University of the Witwatersrand (AESC 2001/32/3, AESC 2003/106/3, AESC 2002/13/3, AESC 2005/82/4, and AESC 2006/3/03).

\section{Literature Cited}

Aikey, J. L., J. G. Nygby, D. M. Anmuth, and P. J. James. 2002. Testosterone rapidly reduces anxiety in male house mice (Mus musculus). Hormones and Behavior 42:448-460.

Bennett, N. C., B. C. Clarke, and J. U. M. Jarvis. 1992. A comparison of metabolic acclimation in two species of social mole-rats (Rodentia, Bathyergidae) in southern Africa. Journal of Arid Environments 22:189-198.

Boonstra, R., C. J. McColl, and T. J. Karels. 2001. Reproduction at all costs: the adaptive stress response of male arctic ground squirrels. Ecology 82:1930-1946.

Brooks, P. M. 1982. Aspects of the reproduction, growth and development of the four-striped mouse, Rhabdomys pumilio (Sparrman, 1784). Mammalia 46:53-64.

Buchanan, K. L., M. R. Evans, A. R. Goldsmith, D. M. Bryant, and L. V. Rowe. 2001. Testosterone influences basal metabolic rate in male house sparrows: a new cost of dominance signalling? Proceedings of the Royal Society B: Biological Sciences 268:1337-1344.

Buttemer, W. A., L. B. Astheimer, and J. C. Wingfield. 1991. The effect of corticosterone on standard metabolic rates of small passerine birds. Journal of Comparative Physiology Series B 161:427431.

Clutton-Brock, T. H. 1989. Mammalian mating systems. Proceedings of the Royal Society B: Biological Sciences 236:339-372.

Cowling, R. M., J. J. Esler, and P. W. Rundel. 1999. Namaqualand, South Africa: an overview of a unique winter-rainfall desert ecosystem. Plant Ecology 142:3-21.

Creel, S. 2001. Social dominance and stress hormones. Trends in Ecology \& Evolution 16:491-497.

Deerenberg, C., G. F. G. Overkamp, H. G. Visser, and S. Daan. 1998. Compensation in resting metabolism for experimentally increased activity. Journal of Comparative Physiology Series B 168:506-512.

Double, M. C., and A. Cockburn. 2003. Subordinate superb fairywrens (Malurus cyaneus) parasitize the reproductive success of attractive dominant males. Proceedings of the Royal Society B: Biological Sciences 270:379-384.

Evans, M. R., A. R. Goldsmith, and S. R. A. Norris. 2000. The effects of testosterone on antibody production and plumage coloration in male house sparrows (Passer domesticus). Behavioral Ecology and Sociobiology 47:156-163.

Gittleman, J. L., and S. D. Thompson. 1988. Energy allocation in mammalian reproduction. American Zoologist 28:863-876.

Gross, M. R. 1996. Alternative reproductive strategies and tactics: diversity within the sexes. Trends in Ecology \& Evolution 11: 92-98.
Hambly, C., and J. R. Speakman. 2005. Contribution of different mechanisms to compensation for energy restriction in the mouse. Obesity Research 13:1548-1557.

Hammond, K. A., and J. Diamond. 1997. Maximal sustained energy budgets in humans and animals. Nature 386:457-462.

Högstad, O. 1987. It is expensive to be dominant. Auk 104:333-336. Kenagy, G. J., S. M. Sharbaugh, and K. A. Nagy. 1989. Annual cycle of energy and time expenditure in a golden-mantled ground squirrel population. Oecologia (Berlin) 78:269-282.

Knapp, R., and B. D. Neff. 2007. Steroid hormones in bluegill, a species with male alternative reproductive tactics including female mimicry. Biology Letters 3:628-631.

Koprowski, J. L. 2008. Alternative reproductive tactics and strategies of tree squirrels. Pages 86-98 in J. O.Wolff and P. Sherman, eds. Rodent societies: an ecological and evolutionary perspective. University of Chicago Press, Chicago.

Kutsakake, N., and T. H. Clutton-Brock. 2006. Social functions of allogrooming in cooperatively breeding meerkats. Animal Behaviour 72:1059-1068.

McEwen, B. S. 1999. Allostasis and allostatic load: implications for neuropsychopharmacology. Neuropsychopharmacology 22:108124

Moore, M. C. 1991. Application of organization-activation theory to alternative male reproductive strategies: a review. Hormones and Behavior 25:154-179.

Moore, M. C., D. K. Hews, and R. Knapp. 1998. Hormonal control and evolution of alternative male phenotypes: generalizations of models for sexual differentiation. American Zoologist 38:133-151.

Oliveira, R. F., A. F. H. Ros, and D. M. Goncalves. 2005. Intra-sexual variation in male reproduction in teleost fish: a comparative approach. Hormones and Behavior 48:430-439.

Oliveira, R. F., A. V. M. Canario, and A. F. H. Ros. 2008. Hormones and alternative reproductive tactics in vertebrates. Pages 132-174 in R. F. Oliveira, M. Taborsky, and H. J. Brockmann, eds. Alternative reproductive tactics. Cambridge University Press, Cambridge.

Perrin, M. R. 1980. The breeding strategies of two co-existing rodents, Rhabdomys pumilio (Sparrman, 1784) and Otomys irroratus (Brants, 1827). Acta Oecologia 1:383-410.

Reeder, D., and K. M. Kramer. 2005. Stress in free-ranging mammals: integrating physiology, ecology, and natural history. Journal of Mammalogy 86:225-235.

Reyer, H. U., J. P. Dittami, and M. R. Hall. 1986. Avian helpers at the nest: are they psychologically castrated? Ethology 71:216-228.

Romero, L. M. 2002. Seasonal changes in plasma glucocorticoid concentrations in free-living vertebrates. General and Comparative Endocrinology 128:1-24.

Scantlebury, M., J. Speakman, M. Oosthuizen, T. Roper, and N. Bennett. 2006a. Energetics reveals physiologically distinct castes in a eusocial mammal. Nature 440:795-797.

Scantlebury, M., N. C. Bennett, J. R. Speakman, N. Pillay, and C. Schradin. 2006b. Huddling in groups leads to daily energy savings in free-living African four-striped grass mice, Rhabdomys pumilio. Functional Ecology 20:166-173.

Scantlebury, M., J. M. Waterman, and N. C. Bennett. 2008. Alternative reproductive tactics in male Cape ground squirrels Xerus inauris. Physiology and Behavior 94:359-367.

Schradin, C. 2004. Territorial defense in a group living solitary forager: who, where, against whom? Behavioral Ecology and Sociobiology 55:439-446.

2005. When to live alone and when to live in groups: eco- 
logical determinants of sociality in the African striped mouse (Rhabdomys pumilio, Sparrman, 1784). Belgian Journal of Zoology 135(suppl.):77-82.

. 2006. Whole day follows of the striped mouse. Journal of Ethology 24:37-43.

- 2008a. Differences in prolactin levels between three alternative male reproductive tactics in striped mice (Rhabdomys pumilio). Proceedings of the Royal Society B: Biological Sciences 275: 1047-1052.

- 2008b. Seasonal changes in testosterone and corticosterone levels in four social categories of a desert dwelling sociable rodent. Hormones and Behavior 53:573-579.

Schradin, C., and G. Anzenberger. 2003. Mothers, not fathers, determine the delayed onset of male carrying in Goeldi's monkey (Callimico goeldii). Journal of Human Evolution 45:389-399.

Schradin, C., and N. Pillay. 2003. Paternal care in the social and diurnal striped mouse (Rhabdomys pumilio): laboratory and field evidence. Journal of Comparative Psychology 117:317-324.

2004a. Prolactin levels in paternal striped mouse (Rhabdomys pumilio) fathers. Physiology and Behavior 81:43-50.

- 2004b. The striped mouse (Rhabdomys pumilio) from the Succulent Karoo of South Africa: a territorial group living solitary forager with communal breeding and helpers at the nest. Journal of Comparative Psychology 118:37-47.

. 2005a. Demography of the striped mouse (Rhabdomys pumilio) in the Succulent Karoo. Mammalian Biology 70:84-92.

- 2005b. Intraspecific variation in the spatial and social organization of the African striped mouse. Journal of Mammalogy 86:99-107.

Shuster, S. M., and M. J. Wade. 1991. Equal mating success among male reproductive strategies in isopods. Nature 350:608-610.

Sinervo, B., D. B. Miles, W. A. Frankino, M. Klukowski, and D. F. DeNardo. 2000. Testosterone, endurance, and Darwinian fitness: natural and sexual selection on the physiological bases of alternative male behaviors in side-blotched lizards. Hormones and $\mathrm{Be}-$ havior 38:222-233.

Speakman, J. R., E. Krol, and M. S. Johnson. 2004. The functional significance of individual variation in basal metabolic rate. Physiological and Biochemical Zoology 77:900-915.

Stopka, P., and R. Graciasova. 2001. Conditional allogrooming in the herb-field mouse. Behavioral Ecology 5:584-589.
Taborsky, M., R. F. Oliveira, and H. J. Brockmann. 2008. The evolution of alternative reproductive tactics: concepts and questions. Pages 1-22 in R. F. Oliveira, M. Taborsky, and H. J. Brockmann, eds. Alternative reproductive tactics. Cambridge University Press, Cambridge.

Thornhill, R. 1981. Panorpa (Mecoptera: Panorpidae) scorpionflies: systems for understanding resource-defense polygyny and alternative male reproductive efforts. Annual Reviews in Ecology and Systematics 12:355-386.

Tomkins, J. L., and G. S. Brown. 2004. Population density drives the local evolution of a threshold dimorphism. Nature 431:1099-1103.

Vermeersch, H., G. T'Sjoen, J. M. Kaufman, and J. Vincke. 2008. The role of testosterone in aggressive and non-aggressive risktaking in adolescent boys. Hormones and Behavior 53:463-471.

Vézina, F., and D. W. Thomas. 2000. Social status does not affect resting metabolic rate in wintering dark-eyed junco (Junco hyemalis). Physiological and Biochemical Zoology 73:231-236.

Wikelski, M., S. S. Steiger, B. Gall, and K. N. Nelson. 2004. Sex, drugs and mating role: testosterone-induced phenotype-switching in Galapagos marine iguanas. Behavioral Ecology 16:260-268.

Wingfield, J. C., and R. M. Sapolsky. 2003. Reproduction and resistance to stress: when and how. Journal of Neuroendocrinology 15: 711-724.

Wingfield, J. C., R. E. Hegner, A. M. Dufty, and G. F. Ball. 1990. The "challenge hypothesis": theoretical implications for patterns of testosterone secretion, mating systems, and breeding strategies. American Naturalist 163:829-846.

Young, A. J., A. A. Carlson, S. L. Monfort, A. F. Russell, N. C. Bennett, and T. Clutton-Brock. 2006. Stress and the suppression of subordinate reproduction in cooperatively breeding meerkats. Proceedings of the National Academy of Sciences of the USA 103: 10225-12010.

Young, A. J., G. Spong, and T. Clutton-Brock. 2007. Subordinate male meerkats prospect for extra-group paternity: alternative reproductive tactics in a cooperative mammal. Proceedings of the Royal Society B: Biological Sciences 274:1603-1609.

Associate Editor: Elizabeth Adkins-Regan Editor: Michael C. Whitlock

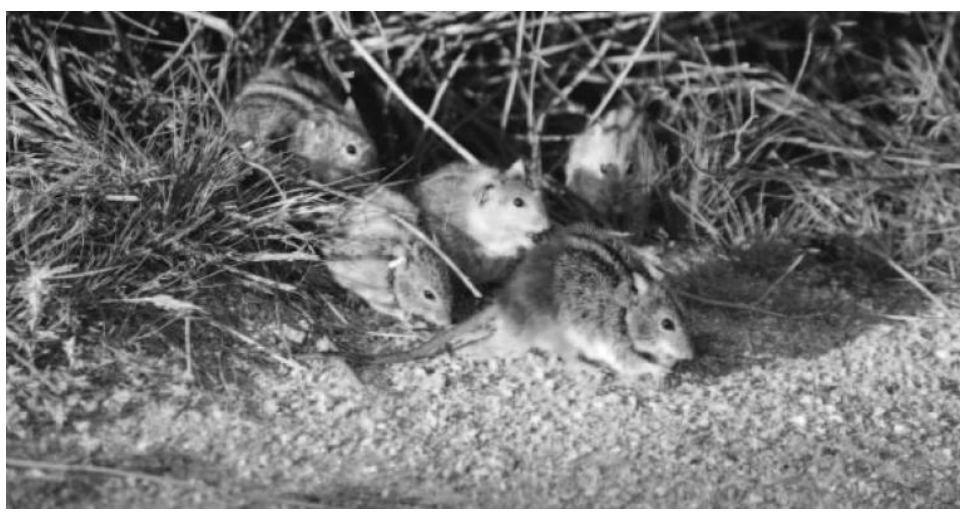

A social male (in front) with his harem of four females. Photograph by C. Schradin. 